\title{
Innovation Research on Business Technology Standards: In the Industrial Clusters Environment
}

\author{
Xuan $\mathrm{Wu}^{1, \mathrm{a}^{*}}$, Qingman $\mathrm{Li}^{2, \mathrm{~b}}$ \\ ${ }^{1}$ Management College of Bohai University Jinzhou, Liaoning \\ ${ }^{2}$ Management College of Bohai University Jinzhou, Liaoning \\ a2224175207@qq.com, blqm5189@163.com
}

Keywords: Technology standards; Innovation; Industrial clusters; Technology standard alliance

\begin{abstract}
Technology standards innovation is an important content to construct an innovative country, which played a significant role in transforming scientific and technological innovations into practical productive process. This paper is begin with the discussion of the characteristics of business technology standards under the industrial clusters environmental; and followed by making analysis to the present situation and existing problem about technology innovation, standardization system, standardization development, innovative talents, research and development funds and so on; finally, from the construction of technology standard alliance, the perfection of system, the innovation of operation mechanism, information management, and talent management, to catch up with the development of business technology innovation driving mode, which is under the industrial clusters environmental. That is to say, the innovation driving mode is dominated by innovative leading enterprises, which is based on professional technical service platform, accordingly to form a technical standard alliance even to build innovation system of technical standards.
\end{abstract}

\section{Introduction}

Along with reform and opening-up degree increase, surrounding the technical standards competition is more and more fierce. Due to the low-level of technology, Chinese enterprises are facing unprecedented challenges about technical standards. Enterprises as the body of technological innovation must assume responsibility for the standard of innovation, combining the standardization work with the development of enterprises. By means of technological innovation to improve product quality and technical level, to accelerate the transformation of scientific and technological achievements into standardization, accordingly step over the technical standards barriers. Therefore, the research of technology standard innovation under the industrial cluster environment has without doubt of great significance to improve the enterprises competitiveness in the market. The innovation of this subject is from the perspective of industrial cluster environmental to study the enterprise technical standards. The subject is a development and extension of network industry perspective. The perspective from the new and high technology industries to the industrial cluster will directly bring the research content and view updates.

\section{The Characteristics of Business Technology Standards under the Industrial Clusters Environmental}

The Connotation of the Technical Standards Innovation. L. Chen (2004) take the telecommunication industry as an example, points out that independent research and development and implement the strategy of standard as the main content of technology standards innovation [1]. Q.M. Li (2013) believes that technical standards innovation refers to the concept of innovation, quality innovation, model innovation and mechanism innovation [2]. The author considers that technology standard innovation as systematic innovation activities, aims to promote technological 
progress, correspondingly improve the quality of related products or services, and then enhance the enterprise economic benefit and social benefit.

The Implication of Industrial Cluster. Cluster is a group of independent business, for gathering funds, personnel, technology and exchange of information and other resources in certain geographical. Industrial cluster is an economy and social phenomenon in a particular area, a large number of companies and related organizations based on specialization, clusters characteristics. The advantages of industrial clusters includes dispersion innovation risk, reduce transaction costs, with unique network structure and significant external economies of scale [3]. More importantly, industrial clusters are playing an increasingly vital role in promoting regional economic development and regional competitiveness.

Characteristics of Business Technology Standards under the Industrial Clusters Environmental. Clusters can strengthen collaboration, competition and the diffusion of technology among cluster enterprises, thereby gain capital support from other enterprises and complementary advantages in the aspects of technology. Industrial clusters of public service platform can provide technical and personnel support for standards research and development, revise, enforcement. Clusters can build technology standard alliance. Through the development and promotion of alliance standards, shape into a regional integrated technology innovation system and adds a powerful driving force for business development.

\section{The Present Situation and Existing Problem about Business Technology Standards under the Industrial Clusters Environmental}

The "12th five" planning indicate that make further step to implement the strategy of intellectual property rights and technology standards, it pointed out the direction for the development of enterprises. Therefore, more and more companies take part in developing the strategy of technology standards, which resulting the rise of standardized demonstration base. These standardized demonstration bases guarantees the implementation of the standardization and popularization. For example, in July 2008, Nanchang high-tech zone by the national standard committee identified as the national tenth high-tech industrial standardization demonstration area, and the national first "national high and new technology industry cluster standardization demonstrative base" [4]. Technology standards is the major force to promote local economic growth and industrial restructuring, but business technology standards in the process of research, development and implementation still faces many problems and the problems are as follows:

The Lack of Independent Innovation and Technology. Technical standards in our country enterprise mostly based on foreign experience to develop and correction. Only through technology introduction and imitation innovation, so that independent design capability is relatively weak, the product added value and technology content is low. The lack of independent intellectual property rights, enterprises are faced with the technical bottlenecks about R\&D, achievements transformation. Take the incubated enterprises invention patent in liaoning province for an example, a total of 310 invention patents in the incubated enterprises in dalian. The amounts of invention patents is in a leading position in the whole province. But other cities on the number of invention patents are small, and even some cities don't have a patent for invention. For example, the city of Yingkou, Jinzhou and Benxi with respectively have three, six and nine patents of invention. What's worse, the city of Fushun, Liaoyang, Panjin and Huludao don't have a patent for invention. From this case, we can conclude that lack of independent innovation and technology is one of the main reason hinder economic balanced development.

Standardization System is not Perfect, the Implementation and Supervision of Standards is not Strong. Standards cross repeat, poor coordination, technology development lack of systematic and targeted. In addition to, low-level in standards implementation and management, the inspection 
and assessment system of corporate standards is not perfect, so that part of the standards can not be effectively applied [5].

Government-led Standards Development, Inter-enterprises and the Enterprise Inter-sector Coordination Mechanisms are Inadequate. Government taking on too much work for the development of standardization, and market players failed to fully stimulate the vitality, hindering the effective of the standardization work. Besides, the market is faced with the problem of uncertainty. This leads confusion for all the participants in the market, range from producers and sellers to consumers [6].

Poor Awareness of the Standardization, the Corporate is Scarcity of Technical Standardization Talent. On the one hand, companies tend to focus only on extensive expansion, in spite of the long-term interests. Enterprises in the aspect of business management and intellectual property protection lack of the consciousness of standardization, resulting in low-product quality, excessive consumption of energy and other resources, hindering the companies long-term development; on the other hand, companies ignore internal personnel training, the coverage of trainers and the training depth is not enough. What is more, talent incentive mechanism and evaluation system which is suitable for business development is not perfect.

Standardization Funding needs to be Improved. Standardization has an important role to enhance the level of the business productivity. Insufficient capital investment directly affects the research, development and implementation of the related standards, so that part of the standard research method lacks progressiveness, science, and even seriously affected the standard publicizing, and popularization of the standardization knowledge. Take all kinds of enterprise R\&D spending as an example, from 2008 to 2013, the enterprise R\&D spending annual growth rate was $15.7 \%, 19.2 \%$, $26.9 \%, 22.1 \%, 25.6 \%, 26.1 \%$. From these data, we can see that with R\&D spending increase every year, but the annual growth rate is not increased. For example, in 2012 only increased by 19.2 percent over the previous year, which increased by 26.9 percent. We can acknowledged that different enterprise's put different emphasis on R\&D spending, which leads to the research and development spending on unbalanced phenomenon [7].

\section{The Path for Technology Standards Innovation under the Industrial Cluster Environment}

Enterprise standardization work determines the standardization in the enterprise status and existence value. Enterprise standardization work involves the production of the enterprise sales, management, technology and other fields, its ultimate goal is to standardize enterprise management, improve the management level of enterprises. Seek the path for technological standard innovation is playing increasingly essential role in promoting the development of the companies.

Strengthen the technology standard alliance as the core role to promote standard innovation. Through technical innovation cooperation between cluster enterprises, to establish long-term and stable cooperative mechanism of the technological innovation, accordingly reduce the risk of R\&D in the technological innovation activities. Based on the regional cooperation and industrial clusters, expanding new members of cluster, accelerating the formation of the cluster chain, and promoting the construction of technical standards system and intellectual property rights system, gradually developed into a integrated platform, which including related technologies, services and products [8]. Leading enterprises in cluster with core technology and products, with the matching of small and medium-sized enterprises to carry out $R \& D$ activities, making the mature technology effectively accumulated, and the formation of the intellectual property system, which make a contribute to creating factual standard. In addition to, within the cluster forming technology diffusion between related enterprises, to accelerate the pace of technological innovation and process innovation achievements turns in a timely manner into corporate standards. What is more, technological innovation can promote the standard innovation in clusters, strengthen market competitiveness among cluster enterprises, even promote and integrate the development of the related industries. 
With enterprise as the main body of the technical standard alliance, geared to the needs of the potential market, set up the standard has a strong adaptability, satisfy the interests and requirement of all the parties involved, and expected to realize multi-win-win situation.

Establish Technical Standards as the Main Body, Management Standards and Working Standards Matching Standards System. The standard system not only can improve the quality of products, but also contribute to the promotion of technological innovation and industrial upgrading, optimize the industrial structure. Set up a standardized working group, which is responsible for managing the operation of the enterprise standardization work. Strengthen the management of standardization work team, coordinate to solve the major problems in the process of standardized research and development, for the industrial cluster internal standardization organization guarantee healthy, steady and rapid development. Standardization work performed by the scientific department, which is responsible for planning, organization, and pressing the implementation. Each departments with full-time standardized management personnel, and is responsible for the standardization management of the department, form the division of labor in place, responsibility implementation situation, to supervise and inspect the implementation of standards and assessment, should enhance the supervision of enterprises and ensure that the effect of the implementation of corporate standards, and the standardization work included in performance appraisal objectives, to promote the smooth implementation of standardization work.

Development and Implementation of Technology Standards Strategy Conducive to Long-term Stable Development of Enterprises. Technology standard strategy as the premise of the enterprise technical support to occupy the marketplace has guiding significance. Cooperation to expand the cluster to the application of cluster technical standards in the existing market, cluster cooperation in the existing market can reduce the risk of market uncertainty, strengthen the network within a cluster effect, make its become the factual standard in the market, in order to gain competitive advantage of technology. To strengthen the construction of the industrial chain and technology alliance, strengthen the core enterprise or leading enterprises of the cluster alliance in technological innovation and achievements transformation of leading role, within the coalition on shared intellectual property study, digestion, absorption and re-innovation, improve enterprise proportion of their own intellectual property rights in the alliance, and lay a solid foundation for the further standards innovation; In addition to, through the cluster technology alliances can weaken the standard competition, is conducive to the rapid accumulation of the user base and increase the probability of technology lock, thus further expanding the scale of the network [9].

Strengthening the Body Role of Business in the Standard-setting Process. The government should gradually decentralization to the market, while the government should put the limited resources and energy to develop the major standards, such as national standards, industry standards, and local standards. Enterprises should participate in the development of enterprise standards, because companies have a good knowledge of the potential demand of customers, make the standard more close to reality. With the standard, the enterprise will be more willing to innovate, will be more subjective initiative into full play. Around the standard of international attention, enterprise should actively participate in the development of international standards, or even leading standards of international coordination activities. Only in this way, the companies are able to strengthen international cooperation, to eliminate potential barriers to trade, to promote the development of international trade, and to enhance the suitability and effectiveness of the standard.

Strengthening Technical Standard Innovative Talent Team Construction, Improve Standardization Consciousness. Technology standard innovation requires a lot of standardized innovative talents as a guarantee and technical support. On the one hand, cultivating standardization of innovative talents. Innovative talents are able to add standardized enterprise vitality, and promote regional economic growth. Technology innovation talents training help to carry out standardization activities, to improve the scientific and technical personnel and management staff awareness of enterprise standardization level, and to cultivate a large number of innovative talents can effectively 
participate in standardization activities, as well as the standardization of enterprise knowledge technology popularization personnel, to achieve the optimal allocation of talent [10]. On the other hand, the business should to establish talent assessment system and incentive mechanism. In terms of achievements to formulate corresponding encouraging policies, such as increasing researchers achievements earnings ratio, so as to arouse the enthusiasm of scientific and technological personnel to carry out the work and creativity.

Strengthening the Information Management System of Technical Standards, Improve the Level of Information. Internet can avoid information asymmetry, moral hazard caused by adverse selection. By applying the network technology into industrial clusters, the industry chain can achieve integration. Establish the data sharing platform of the technology standards, it not only to facilitate the communication of the daily work, but also will be promptly release the revised information about technical standards on the cluster Internet [11]. In this way, it can enhance the ability to access the required data about standard research, develop and assessment, so that improve the level of research and revision capabilities on standards. In addition to, the industrial groups can achieve seamless integration of information about technology standards. Accelerate the production process of information processing, resource management, the comprehensive integration of information technology and collaborative applications, to promote enterprise development model innovation, greatly improve the level of product design and development.

Strengthening Enterprise Standardization Research Support. To enhance investment in scientific research funds is favorable to promote enterprise technology innovation and standard innovation. Firstly, innovation R\&D incentive system should be established, so as to arouse the enthusiasm of technological personnel to carry out the work; Secondly, we must strengthen standardization innovation investment in research and development and special funds support, in the aspect of technical reform, technical innovation, new product development and so on to give a certain amount of money support, such as discount, subsidies and other ways to achieve; Finally, clearly define the main body status of enterprises in advancing the standard innovation, promote mutual coordinated development of technology innovation and standard innovation. Through scientific and technological innovation, improve the overall level of the standard and strengthen the ability of technical standards innovation.

\section{Summary}

Enterprise's development cannot leave the innovation of the technology standard, our country enterprise in the aspect of technology or standard not in line with international standards. Therefore, enterprises should give full play to the advantages of industrial cluster, constantly improve the innovation system of technical standards, enhance the independent innovation ability of the enterprise, accordingly improve its competitiveness in the international and domestic. Only in this way, can we promote enterprise stable, sustained and rapid development.

\section{Acknowledgements}

Fund project: The national social science fund project (14BGL179), the ministry of education of humanities and social science fund project (12YJA630060)

\section{References}

[1] L. Chen and J. Tang, Scientific Management Research , Vol.22 (2004) No.5, p.22-25. (In Chinese)

[2] Q.M. Li and H.J. Wang, Standard Science, (2013) No.1, p.69-73. (In Chinese)

[3] W.H. Chen, Research on Industrial Custer Governance (Economic management publications, Beijing 2007), pp.28-29, (In Chinese) 
[4] Information on http://www.ncpbs.com

[5] X.J. Yang and Z.Y. Li, Management of Agricultural Science and Technology, Vol.30 (2011) No.2, p.18-20. (In Chinese)

[6] V.K. Narayanan and T.X. Chen, Research Policy, Vol.41 (2012), p.1375-1380

[7] Information on http://www.gov.com

[8] K. Kramer and H. Helmers, Science Direct, Vol. 98 (2013), p. 434-439

[9] S. Li: Construction of Enterprise Innovation Management Model and Path Integration Based on the Technological Standards (MS., University of Jilin, China 2013), p.30-34. (In Chinese)

[10]J.G. Gao, Research and Development Management, Vol.24 (2012) No.1, p.11-16. (In Chinese)

[11]S. Hui and C.L. Wei, Science \& Technology Progress and Policy, Vol.30 (2013) No.15, p.19-24. (In Chinese) 